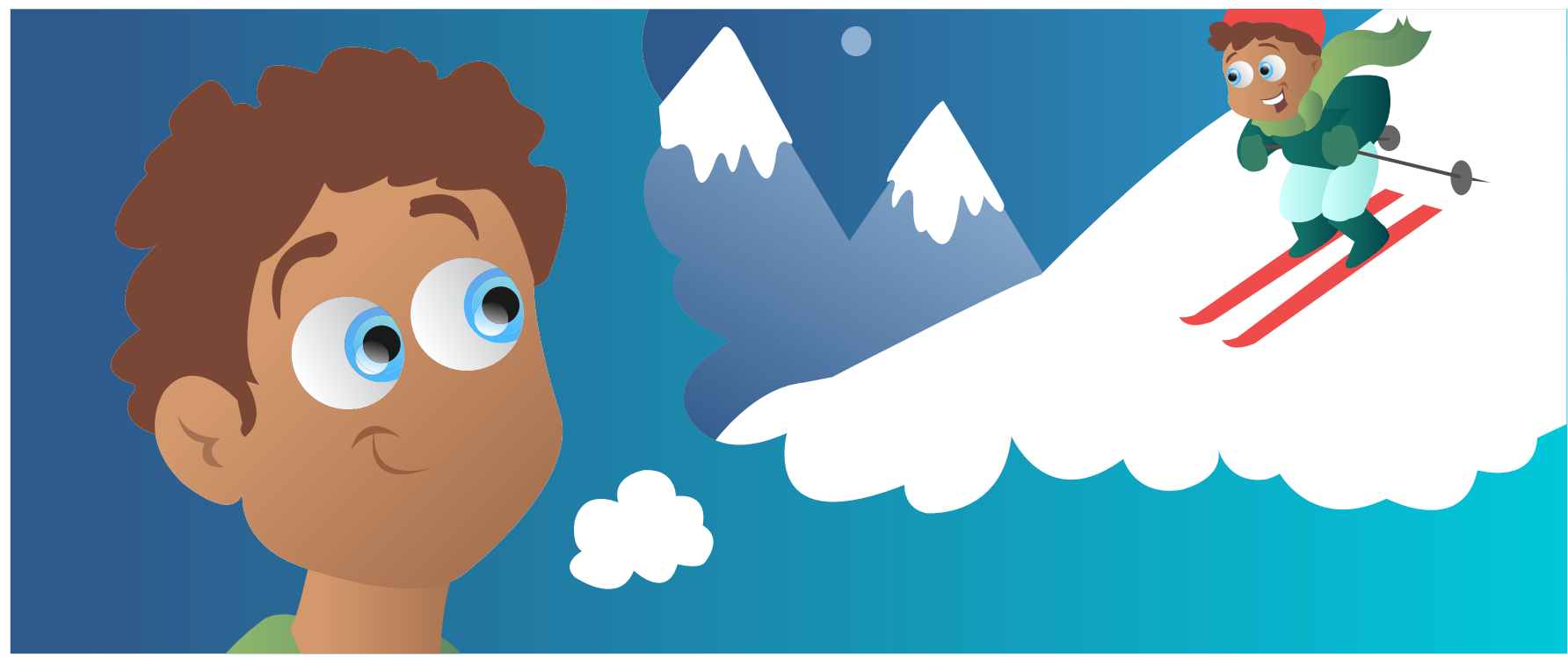

\title{
HOW TO EXERCISE BY IMAGINING
}

\section{MOVEMENTS}

\section{Silvia Erika Kober ${ }^{1,2^{*}}$ and Guilherme Wood ${ }^{1,2}$}

${ }^{1}$ Department of Psychology, University of Graz, Graz, Austria, ${ }^{2}$ BioTechMed-Graz, Graz, Austria

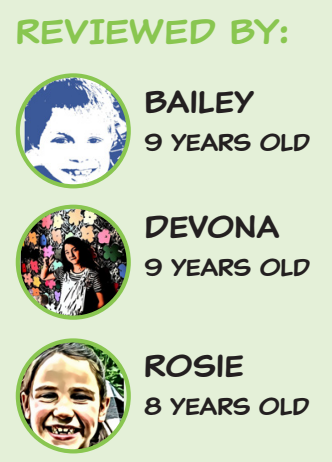

When you shoot some hoops or kick a ball, the areas in your brain responsible for planning, coordinating, and performing movements are active. These are the so-called motor areas. But the motor areas are not only involved when you actually perform a movement, they are also activated when you imagine performing movements. The fact that actual movement and imaginary movement activate similar brain areas can be used to improve motor functions, such as hand or foot movements. When motor areas of the brain are damaged due to an injury, for example, if you hurt your head during an accident, your motor functions might be impaired. So, you have to have physiotherapy to relearn how to perform specific movements and let injured brain areas recover. Recovery can be boosted by additionally imagining moving the affected limb. This therapy is called movement imagery. Movement imagery activates injured brain areas and leads to improvements in motor functions. This is how exercising using movement imagery works.

Imagine bending down low and then jumping straight up in the air as high as possible, with both arms extended above your head. Then imagine how it feels to land with your feet apart and to lower your arms to your sides. Your 
MOTOR IMAGERY

Imagining movements without actually doing them.

\section{MOTOR SKILL}

Learning how to coordinate muscles to control and perform specific movements such as walking, picking up a glass, playing tennis, or skiing.

\section{BRAIN INJURY}

The brain can be damaged for instance by bumping the head and getting a concussion, or when there is a glitch in the blood supply to the brain (which is also called a stroke).

\section{MOTOR CORTEX}

Specific areas in the brain responsible for planning, controlling, and performing movements.

\section{FIGURE 1}

Brain areas involved in movement control.

The premotor cortex and the supplementary motor area are primarily involved in planning and coordinating movements. The primary motor cortex sends commands to the muscles to perform movements. Different parts of the primary motor cortex control different muscles of the body, as indicated by the words in yellow. mind has the awesome ability to imagine such a movement without actually performing it by muscular activity. Imagining movements without actually doing them is called "motor imagery" [1].

Scientists have discovered that motor imagery is important for learning motor skills, such as serving the ball in tennis, perfecting a pirouette in ballet, or even relearning to pick up a glass of water after a brain injury $[1,2]$. But how can the simple process of imagining movements improve motor skills? The answer lies in the brain, which is responsible for planning, coordinating, and performing movements.

\section{HOW THE BRAIN CONTROLS MOVEMENTS}

Specific areas in the brain are responsible for planning, controlling, and performing movements (Figure 1). The premotor cortex (Figure 1, green part of the brain) is involved in preparation and planning of movements, but it also has a role in controlling movements. The supplementary motor area or SMA (Figure 1, yellow part of the brain) plans single movements and sequences of movements and coordinates the left and right sides of the body. The primary motor cortex (Figure 1, blue part of the brain) gives the commands to the muscles to perform movements. Different parts of the primary motor cortex control different muscles. For instance, the muscles of the feet are controlled by the upper parts of the primary motor cortex near the top of the head, while facial muscles are controlled by the lower parts of the primary motor cortex, next to the ear (Figure 1). Generally, "simple" movements, such as picking up a glass, happen in a relatively automatic and unconscious way, meaning that you do not have to concentrate or focus very much to perform simple movements. But, even for something as simple as picking up a glass, complex mechanisms

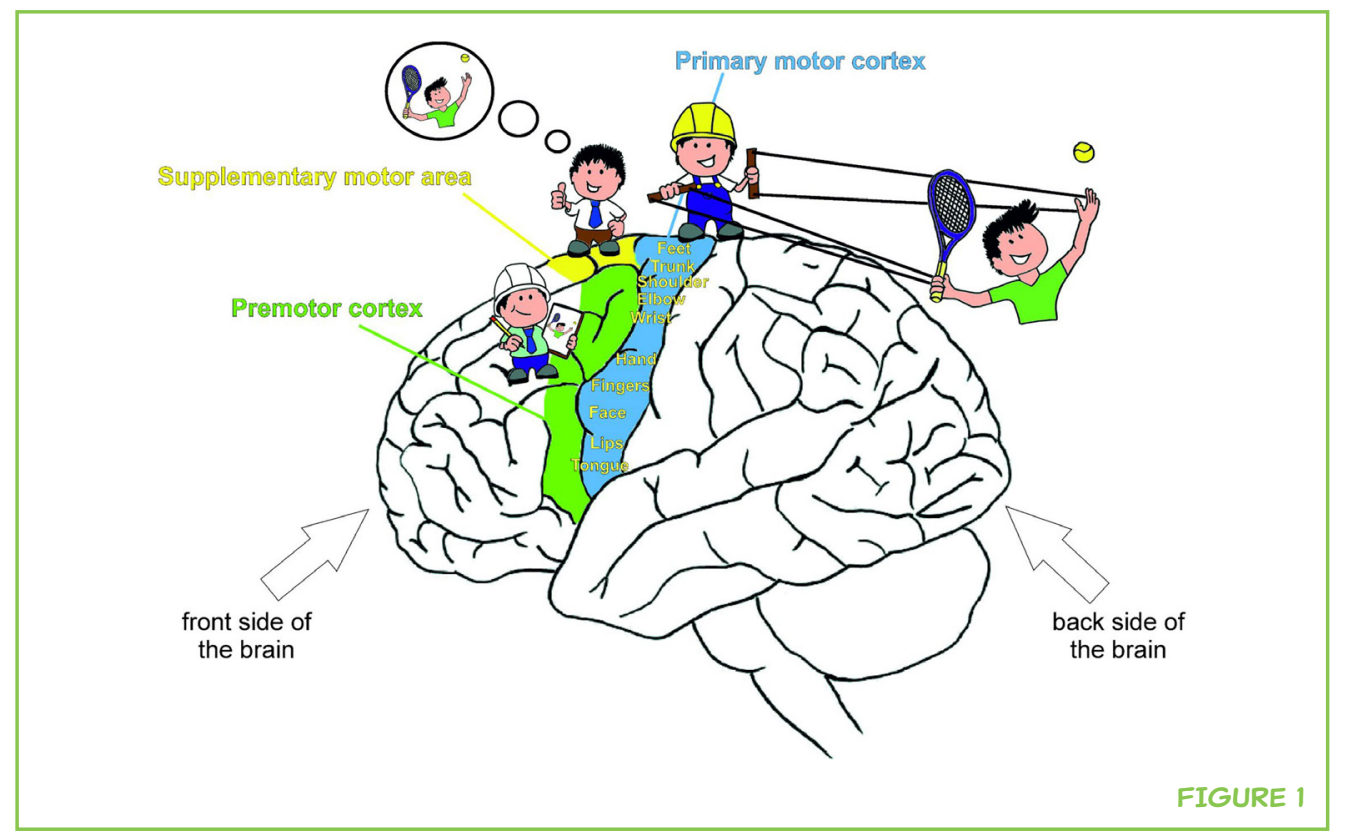


and interactions in the brain are necessary to successfully perform the grasping movement, which activates a large network in the brain. This brain network also includes brain areas other than the ones mentioned above, which we will not described in detail here [3].

If you want to move your hand to serve in tennis, the premotor and supplementary motor areas plan the movement first. Then, the hand area of the primary motor cortex becomes active. It receives input from the other brain areas that have planned and prepared the movement. Finally, the hand area of the primary motor cortex sends commands to your hand muscles via the nerves, telling your hand to stretch and bend. But the hand area in the primary motor cortex is not only active when it is sending actual movement commands to the muscles, it also becomes active when imagining a hand movement, even if the muscles aren't actually moving. To stop the body from actually performing the hand movements during motor imagery, other brain areas can prevent the motor commands from being sent to the muscles [1]. There are many studies showing that during both performance and imagination of specific movements, the primary motor cortex is activated in much the same way [2]. This is the basic reason why we can use motor imagery to improve motor functions.

\section{HOW MOTOR IMAGERY IS USED TO IMPROVE MOTOR SKILLS}

When learning a new movement or motor skill, for example, skiing, you practice the basic skiing posture by bending your knees and leaning forward slightly. Then, you learn how to stop by twisting your feet and pointing the tops of your skis together. To turn, you have to point your feet and your skis in the direction you want to travel. While practicing these skiing movements, your primary motor cortex is active (Figure 2, left picture). Repeating these movements not only strengthens the muscles in your legs and feet, it also strengthens the connections in your brain that are important for mastering these specific movements [4]. Improving the connections between the brain cells in the primary motor cortex leads to better planning and controlling of the movements and to better performance of the movements.

As we said above, imagining movements activates the primary motor cortex in a similar way as actual performance of the movements (Figure 2). So, if you imagine how it feels to bend your knees and to move your feet in a specific direction during skiing, the same brain areas are activated as during real skiing (Figure 2, right picture). And this activation of the primary motor cortex during motor imagery also strengthens the connections in your brain, making it easier to plan, control, and carry out the skiing movements - the same way that these functions are strengthened if you actually perform the movements over and over. This is why you can improve motor skills by motor imagery [2]. 
FIGURE 2

Performing a movement such as skiing (left picture) activates the primary motor cortex (red circle marked in the brain) in a similar way as imagery of the movement (right picture).

\section{PARALYSIS}

Loss of muscle function for one or more muscles so that you cannot move these muscles any more.

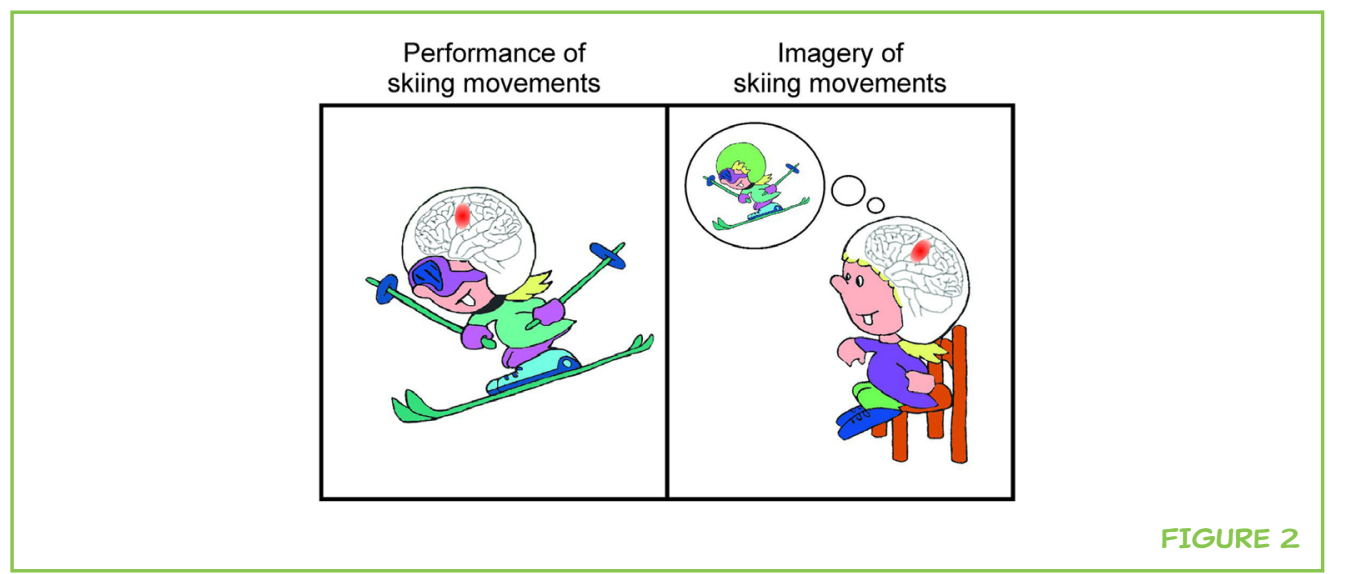

\section{USING MOTOR IMAGERY TO RECOVER MOVEMENTS AFTER BRAIN INJURY}

When areas of the motor cortex are damaged, e.g., by bumping your head and getting a concussion, or when there is a glitch in the blood supply to the brain (which is also called a stroke [4]), motor functions might be damaged. For instance, injury to the hand area of the primary motor cortex can lead to paralysis of the hand, meaning that the primary motor cortex can no longer send effective movement commands to the muscles of the hand. In this case, patients with this kind of brain injury go to physiotherapy to learn how to actively move their paralyzed hand. Sometimes, this therapy involves letting the paralyzed hand be moved by a machine. Performing these hand movements, whether done by the patient or by the machine, activates the primary motor cortex and new brain connections develop. These new connections help the primary motor cortex to successfully send movement commands to the muscles of the hand again. After weeks or months of movement training, hand function normally improves or even completely recovers, due to this physical training.

Motor imagery can also be used to improve motor functions after a brain injury. Most brain injury patients who have a paralyzed hand still remember what it felt like to make specific hand movements. This is great, because they can use this ability to imagine those hand movements and activate the primary motor cortex. In the same way that actually performing hand movements during physiotherapy helps to build connections in the brain, imagining hand movements can build new brain connections, too, which also helps to improve hand function [2].

Most of the studies that have been done used motor imagery to improve hand and foot movements after brain injury [2]. Recent studies performed by our research group show that motor imagery can also be used with swallowing movements, to restore swallowing functions in stroke patients $[5,6]$. Patients with brain injuries often show difficulties in swallowing, which is called 


\section{DYSPHAGIA}

Difficulty in swallowing food or liquids. Patients with brain injuries often show such difficulties in swallowing. dysphagia. So, patients with dysphagia have a hard time when trying to eat or drink, because at any time, the food and drink can go down the wrong pipe and make them choke. We have only one throat, but we have two pipes in there: the esophagus, to transport what we eat and drink to the stomach, and the windpipe, which goes to the lungs, for breathing. People with dysphagia often choke because the food and liquids go down their windpipe and not their esophagus. The swallowing muscles generally control whether the food or liquids go into the esophagus or into the windpipe. These muscles are not working properly in dysphagia patients, and, in addition to choking, dysphagia can lead to malnutrition and a bad state of health. Just like with hand and foot movements, you can also train your swallowing muscles by motor imagery of swallowing movements $[5,6]$.

\section{CAN I REPLACE MY SPORTS CLASSES WITH MOTOR IMAGERY?}

No! Motor imagery cannot replace physical activity. So, you cannot lose weight or improve your physical fitness by just imagining yourself jogging! But motor imagery can support the development of motor skills and can help with the recovery of motor functions after brain injuries [2]. Motor imagery can boost and support the effects of physical exercise and can help you to develop your motor skills in sports, or can even help you play a musical instrument! Motor imagery is a valuable tool that can help you to improve any activity that involves movement.

\section{ACKNOWLEDGMENTS}

This work was supported by BioTechMed-Graz, Austria. Possible inaccuracies of information are under the responsibility of the project team. The text reflects solely the views of its authors.

\section{REFERENCES}

1. Guillot, A., Di Rienzo, F., MacIntyre, T., Moran, A., and Collet, C. 2012. Imagining is not doing but involves specific motor commands: a review of experimental data related to motor inhibition. Front. Hum. Neurosci. 6:247. doi:10.3389/ fnhum.2012.00247

2. Munzert, J., Lorey, B., and Zentgraf, K. 2009. Cognitive motor processes: the role of motor imagery in the study of motor representations. Brain Res. Rev. 60(2): 306-26. doi:10.1016/j.brainresrev.2008.12.024

3. Birbaumer, N., and Schmidt, R. 2006. Biologische Psychologie. 6th ed. Heidelberg: Springer-Verlag.

4. Weishaupt, N., and Zhang, A. 2016. Why doesn't your brain heal like your skin? Front. Young Minds 4(3):a020602. doi:10.3389/frym.2016.00022 
5. Kober, S. E., Bauernfeind, G., Woller, C., Sampl, M., Grieshofer, P., Neuper, C., et al. 2015. Hemodynamic signal changes accompanying execution and imagery of swallowing in patients with dysphagia: a multiple single-case near-infrared spectroscopy study. Front. Neurol. 6:1-10. doi:10.3389/ fneur.2015.00151

6. Kober, S. E., Gressenberger, B., Kurzmann, J., Neuper, C., and Wood, G. 2015. Voluntary modulation of hemodynamic responses in swallowing related motor areas: a near-infrared spectroscopy based neurofeedback study. PLoS One 10(11):1-17. doi:10.1371/journal.pone.014331

SUBMITTED: 27 March 2017; ACCEPTED: 17 July 2017; PUBLISHED ONLINE: 03 August 2017.

EDITED BY: Rich Ivry, University of California, Berkeley, United States.

CITATION: Kober SE and Wood G (2017) How to Exercise by Imagining Movements. Front. Young Minds 5:42. doi:10.3389/frym.2017.00042.

CONFLICT OF INTEREST STATEMENT: The authors declare that the research was conducted in the absence of any commercial or financial relationships that could be construed as a potential conflict of interest.

COPYRIGHT @ 2017 Kober and Wood. This is an open-access article distributed under the terms of the Creative Commons Attribution License (CC BY). The use, distribution or reproduction in other forums is permitted, provided the original author(s) or licensor are credited and that the original publication in this journal is cited, in accordance with accepted academic practice. No use, distribution or reproduction is permitted which does not comply with these terms.

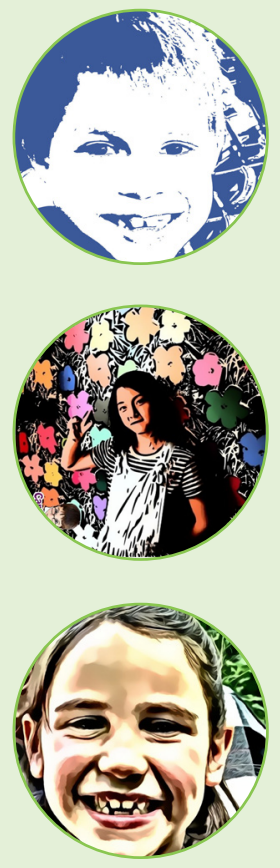

\section{REVIEWED BY}

\section{BAILEY, 9 YEARS OLD}

I am a third grader who likes all things sports, loves to go to amusement parks, and loves the outdoors. I have a sister who is sometimes nice, two parents who are mostly nice, and a group of friends who are always nice. When I grow up you are going to see me on TV playing sports - when I am not working in the lab as a scientist.

\section{DEVONA, 9 YEARS OLD}

Devona is an active 9 years old who loves to play soccer and tennis. She also loves to express herself through art and crafts.

\section{ROSIE, 8 YEARS OLD}

I am a second grader who works hard in school, so that I can grow up to be a scientist. I love to laugh, especially with my friends. My favorite sport is basketball, but I also love to play soccer and ride my bike. 


\section{AUTHORS}

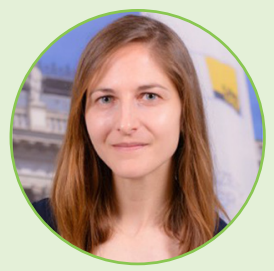

\section{SILVIA ERIKA KOBER}

I am a neuroscientist and a clinical and health psychologist. I work at the Department of Psychology of the University of Graz, Austria. I am interested in the development and evaluation of new rehabilitation tools for patients with brain injuries. Therefore, I am using different techniques such as virtual reality or systems that allow interactions between humans and computers, which are called human-computer interfaces. *silvia.kober@uni-graz.at

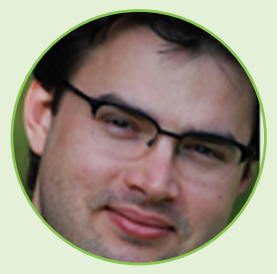

\section{GUILHERME WOOD}

I am a neuroscientist and psychologist. At the Department of Psychology of the University of Graz, Austria, I am leading the working group called Applied Neuropsychology. I am focusing my research on the impact of aging on the brain, how the brain processes numbers, and the genes that are involved in brain activity. Furthermore, my recent research interest focuses on the development and evaluation of new rehabilitation tools for patients with brain injuries. 